\title{
Branched Poly(phenylacetylene)
}

\author{
Marta Angoy, ${ }^{a}$ M. Isabel Bartolomé, ${ }^{a}$ Eugenio Vispe, ${ }^{a}$ Petr Lebeda, ${ }^{b}$ M. Victoria Jiménez, ${ }^{a}$ Jesús J. \\ Pérez-Torrente, ${ }^{a}$ Scott Collins, ${ }^{a}$ and Stepan Podzimek ${ }^{b, c}$
}

aDepartamento de Química Inorgánica, Instituto Universitario de Catálisis Homogénea, Universidad de Zaragoza-C.S.I.C., 50009-Zaragoza, Spain. ${ }^{\mathrm{b}}$ Department of Polymer Materials, University of Chemical Technology, Pardubice, Czech Republic. 'SYNPO, S. K. Neumanna 1316, 53207 Pardubice, Czech Republic

scollins@unizar.es

RECEIVED DATE (to be automatically inserted after your manuscript is accepted if required according to the journal that you are submitting your paper to)

\begin{abstract}
Characterization of poly(phenylacetylene) (PPA) samples produced using Rh(I) complexes featuring hemi-labile phosphine ligands by size exclusion chromatography, multi-angle light scattering, (SEC-MALS), or asymmetric field flow fractionation (A4F)-MALS has revealed that some of these PPA samples contain a mixture of linear and branched polymer. The occurrence and extent of branching is dependent on both catalyst structure and polymerization conditions. The levels of branching are consistent with either terminal branching through copolymerization of macro-monomer or chain transfer to polymer, where the branched species are less reactive towards further polymerization than the linear chains. The MM dependence of B, the number of branches per molecule, or $\lambda$, the number of branches per repeat unit, suggests that the latter explanation may be correct but further work is needed.
\end{abstract}


Introduction. Branched polymers, especially hyper-branched materials, possess significantly different physical properties from their linear isomers, including lower solution or melt viscosity, solubility etc. ${ }^{1}$ These materials find increasing utility as additives for polymer processing, surface coatings, and materials for encapsulation and drug delivery. Hyper-branched materials are generally produced by step growth (co)polymerization of $\mathrm{AB}_{n}(n \geq 2)$ type monomers, or controlled chain growth (co)polymerization involving di- or poly-functional monomers at conversions below the gel point. Another distinctly different approach involves chain-walking, ethylene insertion polymerization using late transition metal, particularly $\mathrm{Pd}-\alpha$-di-imine, catalysts. ${ }^{2}$ Chain transfer to polymer, as occurs in the free-radical initiated polymerization of inter alia ethylene or vinyl acetate, leads to material containing linear, short- and long-chain branched material, ${ }^{3}$ with the largest macromolecules typically possessing the most long-chain branching. ${ }^{4}$ It is also possible to prepare polymers with sparse to dense branching through copolymerization of terminally unsaturated macromonomers with monomer; this process occurs in situ during ethylene polymerization using e.g. constrained geometry catalysts. ${ }^{5}$

Polyphenylacetylene, prepared by transition metal mediated polymerization of phenylacetylene, is an example of a polymer displaying electrical conducting properties. ${ }^{6} \mathrm{PPA}$ is soluble in common organic solvents, is stable in air and displays semi-conductor properties. The conductivity strongly depends on the cis/trans content of the polymer; the conductivity of the all trans polymer is about $10^{10}$ greater than the all cis polymer. ${ }^{7}$ In addition to electrical conductivity, other physical properties such as photoconductivity, optical nonlinearity, liquid crystallinity, gas-selective permeability, or magnetic susceptibility could also be of special importance in such materials. ${ }^{8}$

Several transition-metal based catalysts for the polymerization of substituted acetylenes have been described; examples include Ziegler catalysts, ${ }^{9}$ classical, group 5 or 6 metathesis polymerization catalysts $^{10}$ or well-defined, Schrock-type carbene complexes. ${ }^{11}$ Although there are several initiators that induce stereospecific living polymerization of polyacetylenes, ${ }^{12}$ in general, the reactions are not stereoselective and give mixture of cis and trans polymers. ${ }^{13}$ The reactivity of rhodium(I) complexes towards aryl-acetylenes includes dimerization, cyclization and oligomerization, depending both on the 
structure of the acetylene and the reaction conditions. ${ }^{14}$ Of particular note, rhodium catalysts are also efficient for the polymerization of monosubstituted acetylenes with formation of highly stereoregular polymers, in some cases in a living manner. ${ }^{15}$

Catalysts include cationic rhodium $(\mathrm{I})$ complexes $[\mathrm{Rh}(\operatorname{cod})(\mathrm{N}-\mathrm{N})]^{+}(\mathrm{N}-\mathrm{N}=$ bipy, phen $)$, in the presence of a strong base, such as $\mathrm{NaOH},{ }^{16}$ or others such as $\left[\mathrm{Rh}\left(\mathrm{Tp}^{\mathrm{R} 2}\right)(\operatorname{cod})\right]^{+}\left(\mathrm{Tp}{ }^{\mathrm{R} 2} ; \mathrm{Tp}=\right.$ tris-pyrazolylborate, $\mathrm{R}$ $=\mathrm{Me}, \mathrm{Ph}, i-\mathrm{Pr}),{ }^{17}$ and $\left[\mathrm{Rh}(\right.$ diene $\left.)\left\{\left(\eta^{6}-\mathrm{C}_{6} \mathrm{H}_{5}\right) \mathrm{BPh}_{3}\right\}\right]\left(\right.$ diene $\left.=\mathrm{cod},{ }^{18 \mathrm{a}} \mathrm{nbd}^{18 \mathrm{~b}}\right)$ where a base is not required. Noyori and coworkers reported the living polymerization of PA using the complex $\left[\mathrm{Rh}(\mathrm{C} \equiv \mathrm{CPh})(\mathrm{nbd})\left(\mathrm{PPh}_{3}\right)_{2}\right]$ or the system $[\mathrm{Rh}(\mu-\mathrm{OMe})(\mathrm{nbd})]_{2} / \mathrm{PPh}_{3}$ in the presence of DMAP. ${ }^{19}$ Living polymerization was also achieved using the multi-component initiator system $[\operatorname{Rh}(\mu-$ $\mathrm{Cl})(\mathrm{nbd})]_{2} / \mathrm{Ph}_{2} \mathrm{C}=\mathrm{CPhLi} / \mathrm{PPh}_{3},{ }^{20}$ and the vinyl complexes $\left[\mathrm{Rh}\left\{\mathrm{C}(\mathrm{Ph})=\mathrm{CPh}_{2}\right\}(\operatorname{diene})\left\{\mathrm{PR}_{3}\right\}\right] .{ }^{21,22} \mathrm{We}$ recently reported polymerization studies of $\mathrm{PA}$ employing $\mathrm{Rh}(\mathrm{I})$ complexes 1-5 (Chart I) with hemilabile phosphine ligands; very high molar mass (MM) PPA was produced at high conversion and in the presence of DMAP some of these catalysts polymerize PA in a quasi-living manner. ${ }^{23}$

\section{Chart 1}

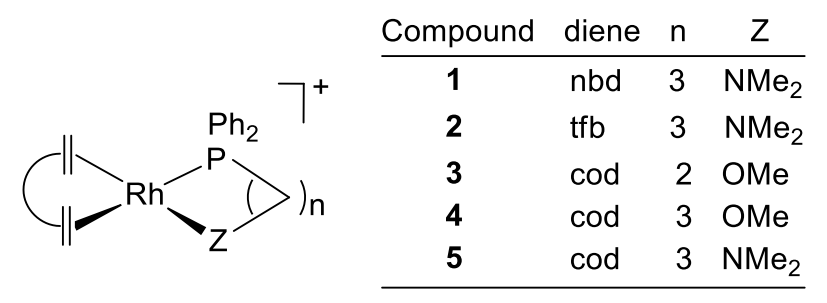

All of these rhodium(I) catalysts are thought to provide linear polymer, and though there has been the suggestion of branching in PPA, prepared using other catalysts, ${ }^{24}$ to the best of our knowledge, the occurrence of branching in PPA has never been documented. We now report the formation of branched poly(phenylacetylene) using $\mathrm{Rh}(\mathrm{I})$ initiators bearing hemi-labile phosphine ligands. The occurrence and extent of branching is dependent on both catalyst structure and polymerization conditions.

Results. The initial detection of branching in these materials resulted from some re-analyses of older samples, prepared in connection with recently published work, ${ }^{23}$ using a SEC system equipped with a miniDAWN ${ }^{\mathrm{TM}}$ three angle, light-scattering, and Optilab ${ }^{\mathrm{TM}}$ refractive index detectors. ${ }^{25}$ At first, it was 
thought that these sensitive materials ${ }^{26}$ might have e.g. cross-linked on exposure to air for long periods of time in the bulk state, but repetition of several polymerization experiments involving different conditions and catalysts, eventually revealed that branched material was being produced during polymerization but not to the same extent by all catalysts or under all conditions.

Specifically, rhodium complex $\quad\left[(\mathrm{nbd}) \mathrm{Rh}\left\{\mathrm{PPh}_{2}\left(\mathrm{CH}_{2}\right)_{3} \mathrm{NMe}_{2}\right\}\right]\left[\mathrm{BF}_{4}\right] \quad(\mathbf{1}), \quad$ or $\quad$ its (tetrafluorobenzo)bicyclo[2.2.2]octadiene (tfb) analogue 2, polymerized PA in dry THF or toluene to produce high MM polymer which possessed a unimodal molar mass distribution (MMD) as indicated by refractive index or light-scattering detectors $\left(\mathrm{M}_{\mathrm{w}}=2.18 \times 10^{6}, \mathrm{PDI}=2.00\right.$ - Figure 1$)$. It should be noted that these conjugated PPA materials interact strongly with the column packing - this was evident from tailing intensity on the light-scattering detectors well beyond the low MM exclusion limit of the column set (three, PLGel Mixed B, $10 \mu$ columns) as well as the increase in MM and $r_{g}$ with elution volume evident at long elution volumes (Figure 1). This interaction can be due to simple enthalpic adsorption, or to anchoring of randomly branched macromolecules in the mesopores; the two effects are difficult to separate..$^{27}$ Due to this interaction, the PDI values based on the SEC analyses are not accurate though they do correlate with the breadth of these distributions.
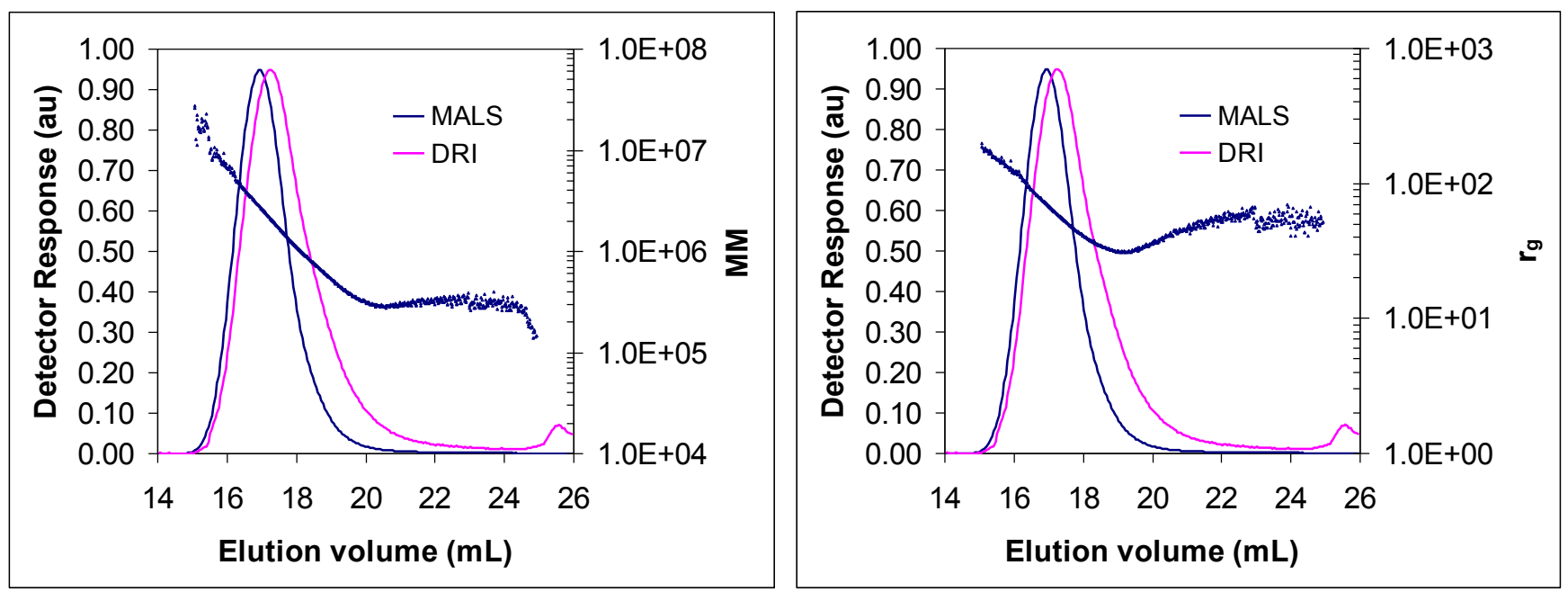

Figure 1. Light scattering (blue) and refractive index (magenta) chromatograms, a) MM and b) $r_{g}$ vs. elution volume (mL) plots for a PPA sample prepared using [(nbd)Rh $\left.\left\{\mathrm{PPh}_{2}\left(\mathrm{CH}_{2}\right)_{3} \mathrm{NMe}_{2}\right\}\right]\left[\mathrm{BF}_{4}\right](\mathbf{1})$ in dry THF. 
As shown in Figure 1, the light-scattering detector revealed detectable increases in $\mathrm{MM}$ on the high MM shoulder of the main peak (Figure 1a) and lesser increases in the radius of gyration $\left(r_{g}\right)$ over the same elution volume (Figure $1 \mathrm{~b}$, note the logarithmic scale for $\mathrm{MM}$ and $\mathrm{r}_{\mathrm{g}}$ ), consistent with the presence of branched material. A log-log plot of $r_{g}$ vs. MM revealed significant deviations from linear behavior in the high molar mass region (Figure 2a) consistent with branching. Interaction of PPA with the column packing accounts for the curious shape of the conformation plot (Figure 2a) in the low molar mass region, since the radius (which is sensitive to the $\mathrm{z}$-average $\mathrm{MM}$ ) vs. mass (which is sensitive to the waverage MM) behavior is somewhat different at longer elution volumes (Figure 1).

Analysis of this sample by A4F-MALS confirmed the initial SEC-MALS results. Since there is no column packing for the sample to interact with, a normal conformation plot was obtained where deviation from linearity is evident at higher molar mass (Figure 2b), consistent with the presence of branching. ${ }^{27}$ Polymerizations in the presence of radical scavengers like BHT did not hinder branch formation (nor polymerization) suggesting that free radical induced, branching was not responsible for this behavior.

Different behavior was observed for PPA samples prepared using [(cod)Rh $\left\{\mathrm{PPh}_{2}\left(\mathrm{CH}_{2}\right)_{2} \mathrm{OMe}\right]\left[\mathrm{BF}_{4}\right]$ (3) or $\left[(\mathrm{cod}) \mathrm{Rh}\left\{\mathrm{PPh}_{2}\left(\mathrm{CH}_{2}\right)_{3} \mathrm{OMe}\right\}\right]\left[\mathrm{BF}_{4}\right](4)$ namely the production of linear PPA of lower $\mathrm{MM}\left(\mathrm{M}_{\mathrm{w}}=\right.$ $1.53 \times 10^{5}$, PDI $=3.09$, Figure 3 ). Here, however, light scattering revealed the presence of a second trace
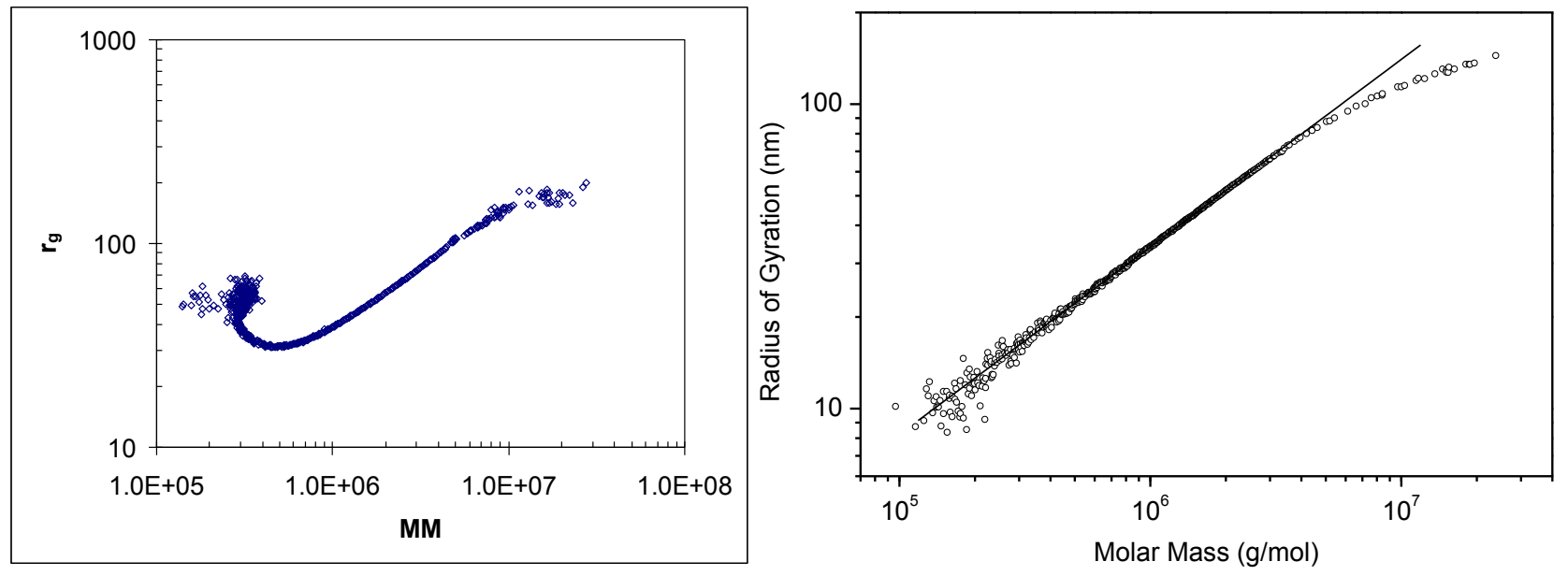
Figure 2. Log-log plots of $r_{g}$ vs. MM for a PPA sample prepared using complex $\mathbf{1}$ in THF analyzed by a) SEC-MALS and b) A4F-MALS. The slope of the linear portion of the latter plot is $\mathrm{m}=0.60 .^{28}$
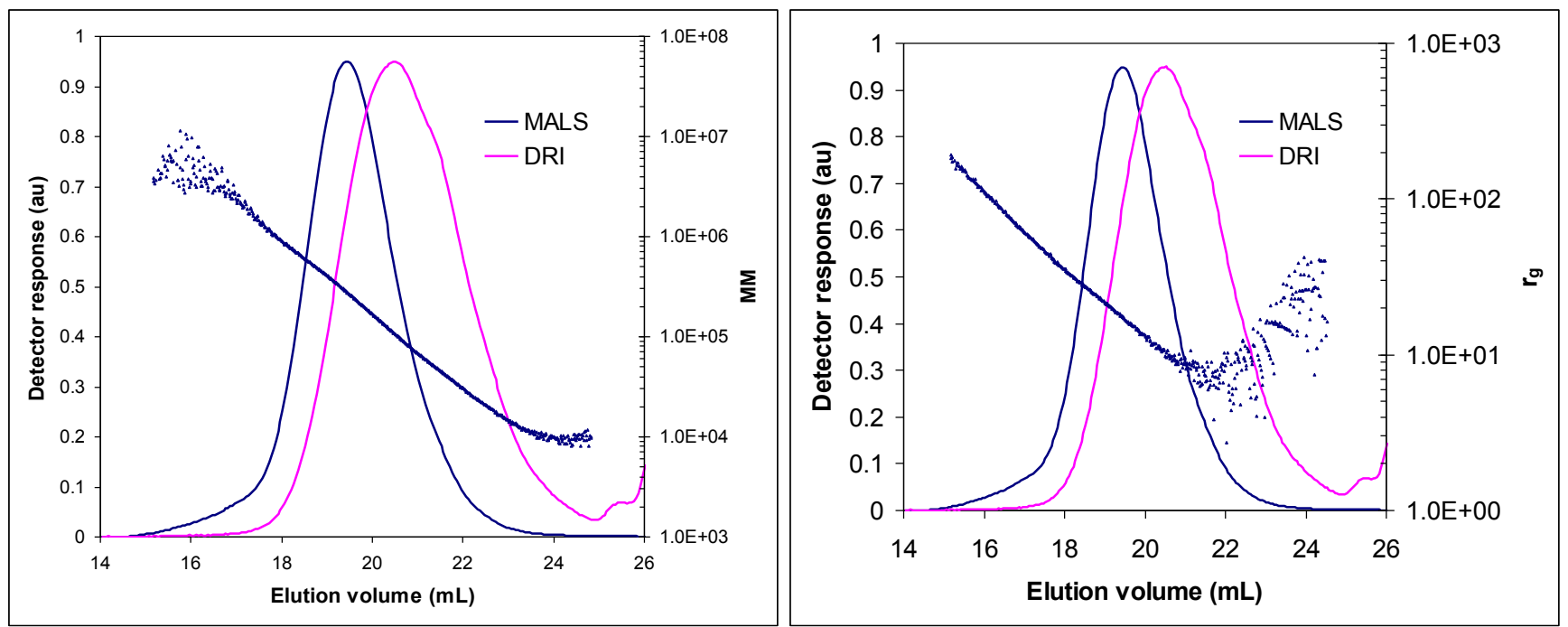

Figure 3. Light scattering (blue) and refractive index (magenta) chromatograms, a) MM and b) $r_{g}$ vs. elution volume $(\mathrm{mL})$ plots for a PPA sample prepared using $\left[(\mathrm{cod}) \mathrm{Rh}\left\{\mathrm{PPh}_{2}\left(\mathrm{CH}_{2}\right)_{2} \mathrm{OMe}\right\}\right]\left[\mathrm{BF} \mathrm{F}_{4}\right](\mathbf{3})$ in dry THF.

component $(<<1 \mathrm{wt} \%$ based on DRI intensity) of higher MM which also appeared linear over the elution volume ranges where both MALS and DRI detectors had detectable intensity. ${ }^{29}$

Finally, the last catalyst investigated $\left[(\mathrm{cod}) \mathrm{Rh}\left\{\mathrm{PPh}_{2}\left(\mathrm{CH}_{2}\right)_{3} \mathrm{NMe}_{2}\right\}\right]\left[\mathrm{BF}_{4}\right](\mathbf{5})$ also afforded PPA with a bimodal MMD by SEC-MALS $\left(\mathrm{M}_{\mathrm{w}}=2.38 \times 10^{5}, \mathrm{PDI}=1.79\right) .{ }^{30}$ Both components appeared linear where both were reliably detected by DRI and MALS, ${ }^{29}$ though as with samples prepared using catalysts $\mathbf{1}$ or $\mathbf{2}$, formation of branched material could be detected at highest MM (Figure 4b). 

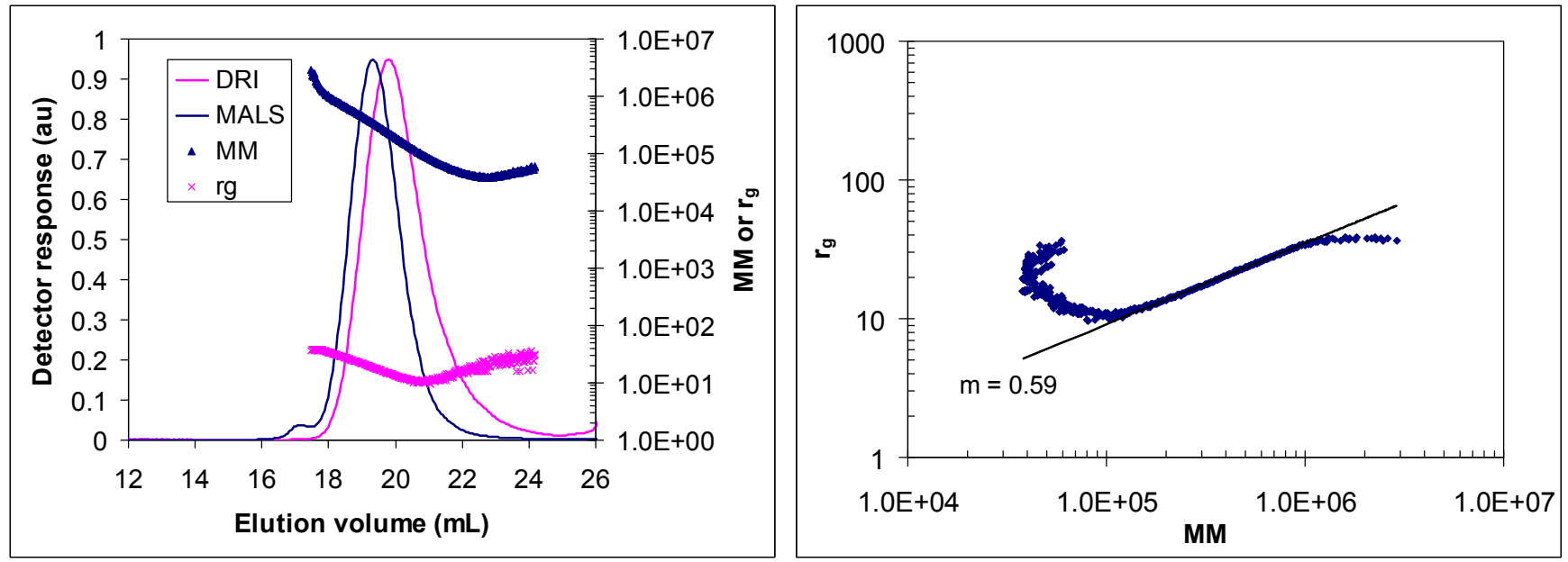

Figure 4. (a) Light scattering (blue) and refractive index (magenta) chromatograms, MM (blue $\times$ ) and $r_{g}$ (magenta $\times)$ vs. elution volume $(\mathrm{mL})$ plot for a PPA sample prepared using $\left[(\mathrm{cod}) \mathrm{Rh}\left\{\mathrm{PPh}_{2}\left(\mathrm{CH}_{2}\right)_{3} \mathrm{NMe}_{2}\right\}\right]\left[\mathrm{BF}_{4}\right](5)$ in dry THF. (b) Log-log plot of $\mathrm{r}_{\mathrm{g}} \mathrm{vs}$. MM for this sample. ${ }^{28}$

Determination of the branching ratio $g=\left\langle R_{b r}^{2}\right\rangle /\left\langle R_{\text {lin }}^{2}\right\rangle$ where $\left\langle R^{2}\right\rangle=r_{g}$ for these materials by SECMALS is complicated by interaction of these materials with the column packing. Essentially $\mathrm{g}>1$ for materials that interact with the column packing and elute at longer elution volumes - a spurious result. Thus, an accurate determination of either average branching frequency per macromolecule $(\overline{\mathrm{B}})$ or branching per repeat unit $\bar{\lambda}$ or the dependency of these variables on MM is not possible.

On the other hand analysis by $\mathrm{A} 4 \mathrm{~F}$ removes this complication. Branching frequencies of a PPA sample prepared using catalyst 1 in dry toluene $\left(\mathrm{M}_{\mathrm{w}} 1.73 \times 10^{6}\right.$, PDI $=3.1$ by $\mathrm{A} 4 \mathrm{~F}$, Figure 5) were calculated from the Zimm-Stockmayer equation, ${ }^{31}$ assuming tri-functional branching and monodisperse slices. These analyses indicated that the average branching frequencies per molecule and per repeat unit were $\overline{\mathrm{B}}=0.89$ and $\bar{\lambda}=0.012$ respectively. This level of branching is consistent with either terminal branching (via copolymerization of unsaturated macro-monomer) or chain transfer to polymer, wherein the branched, propagating species are less reactive than linear chains towards further propagation. The abrupt change in B or $\lambda$ vs. MM (Figure 5) is more consistent with chain transfer to polymer in that the largest, most highly branched macromolecules are statistically more prone to grow further via this process..$^{4-5}$ 
Discussion. There is little doubt as to the nature of the resting state in $\mathrm{Rh}(\mathrm{I})$ mediated PA polymerizations using $\left[(\right.$ diene $\left.) \mathrm{Rh}(\mathrm{L})_{\mathrm{n}} \mathrm{X}\right]$ complexes $\left(\mathrm{n}=1,2 ; \mathrm{X}=\right.$ halide, $\mathrm{C} \equiv \mathrm{CPh}, \mathrm{CPh}=\mathrm{CPh}_{2}, \mathrm{~L}=\mathrm{PR}_{3}$ etc.), thanks to the pioneering work of Noyori and co-workers, where intermediate analogous to 6 was isolated and shown to be competent for polymerization (Scheme 1). ${ }^{19}$ In the case of Noyori's catalyst,

\section{Scheme 1}
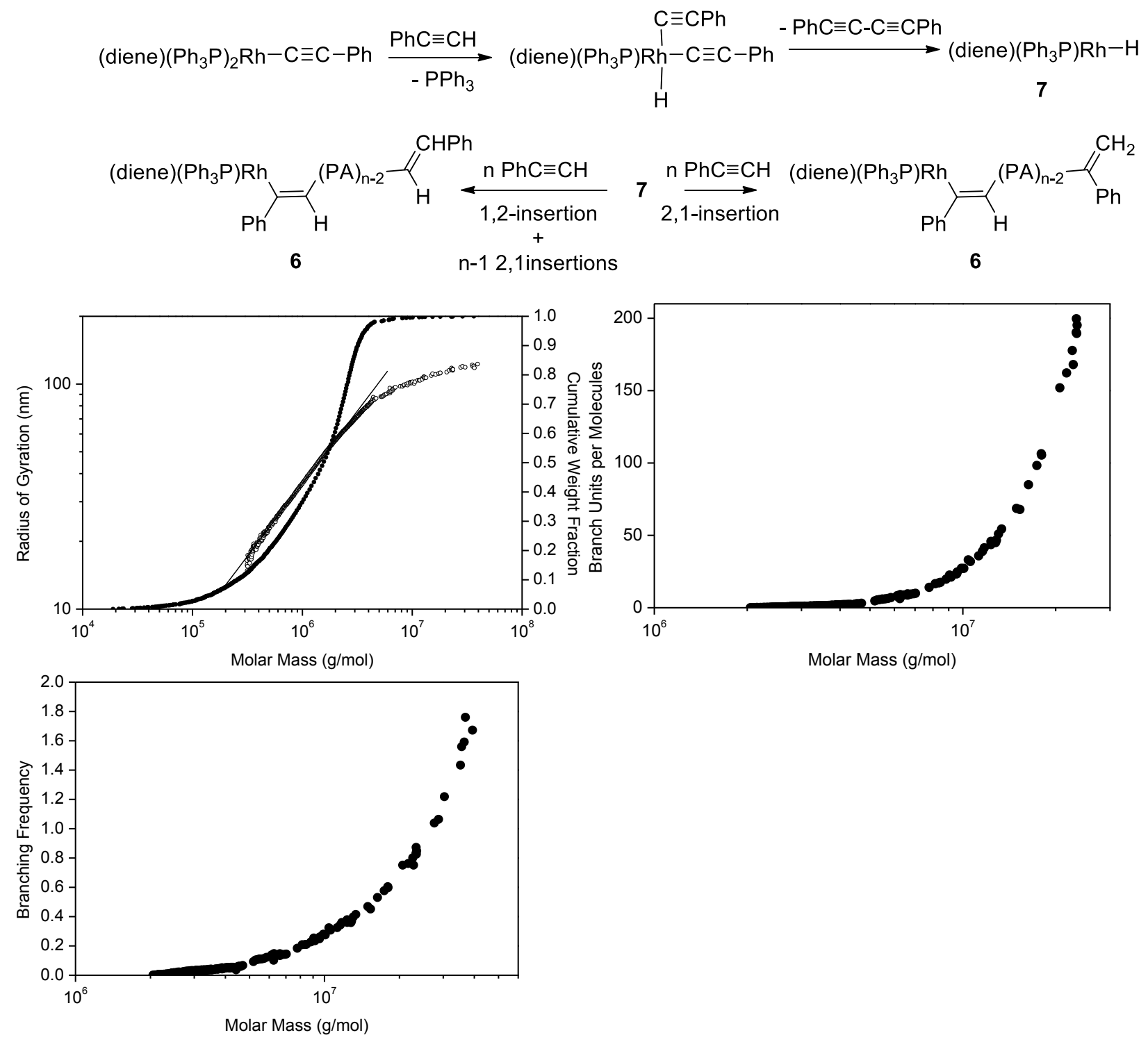

Figure 5. a) Radius of gyration $(\circ)$ and cumulative weight fraction of polymer $(\bullet)$ vs. molar mass obtained from A4F data for a PPA sample prepared using catalyst 1 in toluene. The line represents a linear fit to the data in the range of $22-56 \mathrm{~nm}: \mathrm{r}_{\mathrm{g}}=0.00488 \times \mathrm{MM}^{0.645}\left(\mathrm{THF}, 25^{\circ} \mathrm{C}\right) .28$; b) Branching frequencies per molecule B and c) per repeat unit $\lambda$ vs. MM for this same sample. 
complex 6 was envisaged to form via insertion of PA into Rh-H complex 7, formed via reductive elimination of $\mathrm{PhC} \equiv \mathrm{C}-\mathrm{C} \equiv \mathrm{CPh}$, where 1 equiv. of this diyne is formed per equiv. of living chain.

As shown in Scheme 1, this would result in the formation of a living chain $\mathbf{6}$ with either a cis/transvinylene or vinylidene end-group, depending on the initial regiochemistry of PA insertion into Rh-H. In the absence of DMAP which renders this process living, there is much less known about the chain transfer processes with these catalysts due to the high MW of the polymers typically formed; specifically, the identity of the end groups in the polymer chains, formed via chain transfer, is not known.

Synthesis of sufficiently low MW polymer to conclusively identify end groups in our materials (using e.g. MALDI-TOF mass spectrometry) was precluded by the low initiator efficiency characteristic of these catalysts; ${ }^{23}$ even at low monomer to catalyst ratios of 5:1 $\mathrm{X}_{\mathrm{n}}>500$ for these materials. In the ${ }^{1} \mathrm{H}$ NMR spectrum of some PPA samples prepared using complex $4\left(X_{n} \sim 620\right)$ we were able to detect olefinic signals at $\delta 6.08$ and $5.74 \mathrm{ppm}$, both doublets with $\mathrm{J}=1.1 \mathrm{~Hz}$, which are assigned to $1,3,5$ triphenyl-1,3-cyclohexadienyl groups present at levels of ca. $1.5 \mathrm{~mol} \% .^{26}$ No other (end) groups could be reliably detected.

In the case of $\left[(\mathrm{nbd})\left(\mathrm{Ph}_{3} \mathrm{P}\right)_{2} \mathrm{RhC} \equiv \mathrm{CPh}\right]$ or $[(\mathrm{cod}) \mathrm{RhCl}]_{2} / \mathrm{NEt}_{3}$, it would appear that $\mathrm{Rh}(\mathrm{I})$-mediated dimerization or trimerization of PA to provide rhodacyclopentadienyl ${ }^{19}$ or hydropentalenylrhodium complexes $^{32}$ are examples of catalyst deactivation reactions that are inhibited in the presence of DMAP or sufficient quantities of PA. It is unclear that these reactions are relevant to chain transfer.

Synthesis of PA oligomers $\left(\mathrm{X}_{\mathrm{n}}<15\right)$ using $\mathrm{TiO}_{2}$ supported on silica ${ }^{33}$ or using Ni-acetylide complexes ${ }^{34}$ has indicated that these materials have vinylidene $\left(\mathrm{CH}_{2}=\mathrm{CPh}-\right)$ and acetylene $(-\mathrm{C} \equiv \mathrm{CPh})$ end groups. Depending on the mechanism of initiation (e.g. insertion of PA into Ni-C $\mathrm{CR}^{34}$ vs. insertion of $\mathrm{PA}$ into Ti-H $\mathrm{H}^{33}$ ) and chain transfer (e.g. protonolysis of the chain end by $\mathrm{PA}$ to produce $\mathrm{CH}_{2}=\mathrm{CPh}_{-} \mathrm{PPA}^{34}$ or $\beta$-H elimination in the case of Ti to produce PPA-C $\equiv \mathrm{CPh}^{33}$ ), these same groups are envisaged to form in different ways. Electrocyclization of the chain-end (Cope rearrangement) ${ }^{26}$ so as to generate either 
1,3,5- or 1,2,4-triphenylbenzene by-products ${ }^{33-34}$ has also been suggested as a process involved in chain transfer.

Based upon Noyori's mechanistic work, chain transfer to PA (via protonolysis of the chain end ${ }^{34}$ or formal oxidative addition, reductive elimination) could involve formation of either vinylene or vinylidene end groups depending on the regiochemistry of PA insertion prior to chain transfer. The problem with this scenario is that it presumes that subsequent $\mathrm{PA}$ insertion into $\mathrm{Rh}-\mathrm{C} \equiv \mathrm{CPh}$ is efficient, a process known to be difficult and/or inefficient in the initiators investigated by Noyori and co-workers. ${ }^{19}$ A more appealing alternative involves formation of $\mathrm{Rh}-\mathrm{H}$ complex $\mathbf{7}$, accompanied by reductive elimination of ene-yne functionality (Scheme 2). 


\section{Scheme 2}

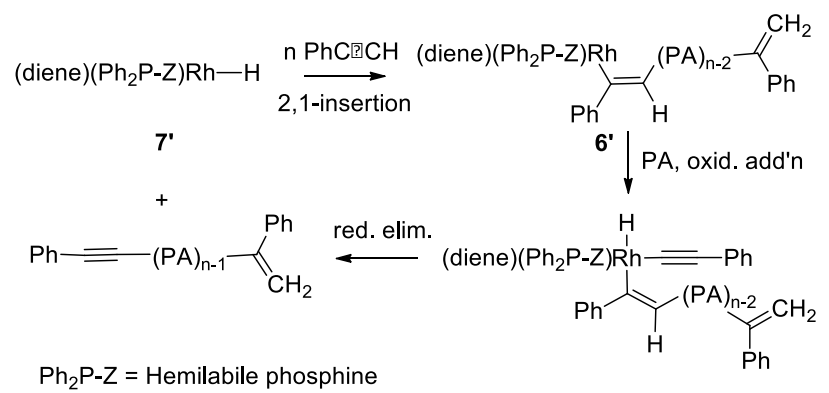

The macromonomer formed as a result of this process has terminal $\mathrm{R}_{2} \mathrm{C}=\mathrm{CH}_{2}$ or $\mathrm{R}-\mathrm{C} \equiv \mathrm{C}-\mathrm{R}$ ' functionality, which might be susceptible to copolymerization leading to terminal branching. Alternately, the Rh-H complex 7' could react at any interior $\mathrm{C}=\mathrm{C}$ bond of any macromolecule to form a $\pi$-allyl complex. This might propagate further (via the $\sigma$-allyl), leading to branch formation. Consistent with either possible process, lower MM PPA prepared using catalyst $\mathbf{5}$ was partially consumed in a subsequent reaction involving catalyst $\mathbf{1}$ and additional monomer; the PPA isolated was composed of higher MW polymer than a blend of similar composition, with increases in the extent of branching (see Supporting Information).

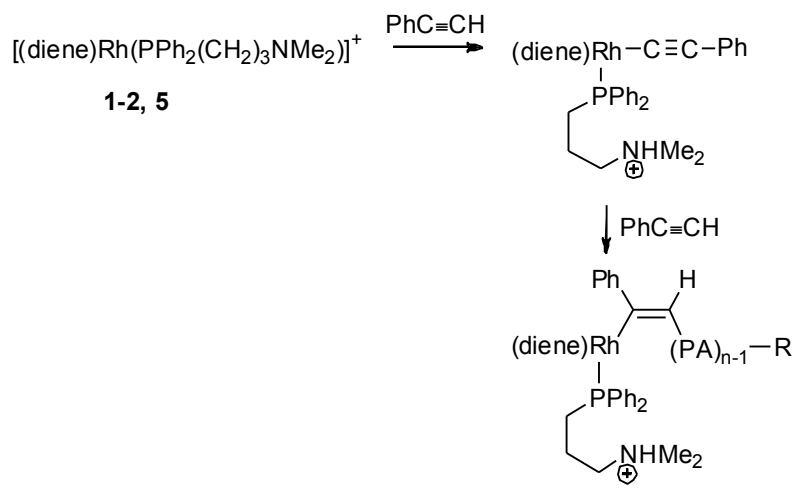

\section{Equation 1}

The susceptibility towards branch formation is obviously catalyst dependent. Complexes such as $\mathbf{1}$ and $\mathbf{5}$ are known to react with PA to afford complexes in which the hemi-labile ligand is protonated at $\mathrm{N}$ $(\text { eqn. 1) })^{23}$ and thus mono-dentate, whereas those such as $\mathbf{3}$ can equilibrate between chelated bi- and mono-dentate forms. We do note that catalysts systems devoid of phosphine donor ligands (e.g. $\left[(\mathrm{nbd}) \mathrm{Rh}-\eta^{6}-\mathrm{C}_{6} \mathrm{H}_{5}-\mathrm{BPh}_{3}\right]$ or $\left.\left[(\mathrm{nbd}) \mathrm{Rh}\left(\mathrm{NCCH}_{3}\right)_{2}\right]\left[\mathrm{BF}_{4}\right]\right)$ produce linear polymer in THF while 
branched (and linear) material was slowly formed using $\left[(\operatorname{cod}) \mathrm{Rh}\left(\mathrm{PPh}_{3}\right)_{2}\right]\left[\mathrm{BF}_{4}\right]$ under the same conditions. Further work will focus on studying those factors which influence the formation of linear vs. branched material and elucidating the mechanism of branch formation in these materials.

Acknowledgments The financial support from Ministerio de Ciencia e Innovación (MICINN/FEDER) is gratefully acknowledged (Project numbers CTQ2009-08089 and CTQ200910132). MA and MIB are thankful for graduate research fellowships provided by Instituto Universitario de Catálisis Homogénea (IUCH). SC acknowledges the support of the Fundación Aragonesa de Investigación y Desarrollo (ARAID) and IUCH.

Supporting Information Available. Experimental details and tables of MM averages for PPA samples prepared, SEC and A4F chromatograms, plots of MM and $r_{g}$ vs. elution volume for all PPA samples analyzed. Details for separation and analyses of these materials by A4F. NMR spectra of PPA. Total 14 pages. This information is available via the World Wide Web at http://pubs.acs.org.

\section{References}

1. Some review articles on hyperbranched polymers: a) Kim, Y. H. J. Polym. Sci.: Part A: Polym. Chem. 1998, 36, 1685-1698. b) Hult, A.; Johansson, M.; Malmström, E. Branched Polymers, 143, 1-34

c) Voit B. J. Polym. Sci.: Part A: Polym. Chem. 2000, 38, 2505-2525. d) Gao, C.; Yan, D. Prog. Polym.

Sci. 2004, 29, 183-275. e) Yates, C. R.; Hayes, W. Euro. Polym. J. 2004, 40, 1257-1281. f) Voit, B. J. Polym. Sci.: Part A: Polym. Chem. 2005, 43, 2679-2699.

2. a) Guan, Z.; Cotts, P. M.; McCord, E. F.; McLain, S. J. Science 1999, 283, 2059-2062. b) Guan, Z. Chem. Eur. J. 2002, 8, 3087-3092. c) Guan, Z. J. Polym. Sci.: Part A: Polym. Chem. 2003, 41, 36803692.

3. Odian, G. In Principles of Polymerization, $4^{\text {th }}$ Ed.; Wiley-Interscience, 2004, p. 250-254.

4. Iedema,P. D.; Wulkow, M.; Hoefsloot, H. C. J. Macromolecules 2000, 33, 7173-7184. 
5. For a review of MM and branching distributions in such materials see Soares, J. B. P. Macromol. Mater. Eng. 2004, 289, 70-87.

6. a) MacDiarmid, A. G. Curr. Appl. Phys. 2001, 1, 269-279. b) Naarmann, H. In Polymers, Electrically Conducting In Ullmann's Encyclopedia of Industrial Chemistry, 6th ed.; Wiley- VCH: Weinheim, 2002, A21, 429-447.

7. Gruber, A. S.; Boiteux, G.; de Souza, R. F.; de Souza, M. O. Polym. Bull. 2002, 47, 529-537.

8. a) Aoki, T.; Kaneko, T.; Teraguchi, M. Polymer 2006, 47, 4867-4892. b) Tang, B. Z.; Lam, J. W. Y. Acc. Chem. Res. 2005, 38, 745-754. c) Choi, S.- K.; Gal, Y. - S.; Jin, S. - H.; Kim, H. K. Chem. Rev. 2000, 100, 1645-1682.

9. Trepka, W. J.; Sonnenfeld, R. J. J. Polym. Sci., Part A- 1:Polym. Chem. 1970, 8, 2721-2244.

10. Shirakawa, H.; Masuda, T.; Takeda, K. In: The Chemistry of Triple-Bonded Functional Groups, Supplement C2, Patai, S. Ed.; Wiley: Chichester, 1994, Chap. 17.

11. a) Schrock R. R. Chem. Commun. 2005, 2773-2777. b) Schrock, R. R.; Luo, S.; Lee, J. C.; Zanetti, N.; Davis, W. M. J. Am. Chem. Soc. 1996, 118, 3883-3895. c) Buchmeiser, M.; Schrock, R. R. Macromolecules 1995, 28, 6642-6649.

12. a) Hayano S.; Masuda, T. Macromolecules 1998, 31, 3170-3174. b) Nakano, M.; Masuda, T.; Higashimura, T. Macromolecules 1994, 27, 1344-1348.

13. Nakayama, Y.; Mashima, K.; Nakamura, A. Macromolecules 1993, 26, 6267-6272.

14. a) Chen, S.; Li, Y.; Zhao, J.; Li, X. Inorg. Chem. 2009, 48, 1198-1206. b) Nishiura, M.; Hou, Z. J. Mol. Catal. A: Chem. 2004, 213, 101-106. c) Lamata, M. P.; San Jose, E.; Carmona, D.; Lahoz, F. J.; Atencio, R.; Oro, L. A. Organometallics 1996, 15, 4852-4856. d) Werner, H.; Schäfer, M.; Wolf, J.; 
Peters, K.; von Schnering, H. G. Angew. Chem., Int. Ed. Engl. 1995, 34, 191-194. e) Schäfer, H. - A.; Marcy, R.; Rüping, T.; Singer, H. J. Organometallic Chem. 1982, 240, 17-25.

15. Taube, R.; Sylvester, G. In Applied Homogeneous Catalysis with Organometallic Compounds, 2nd ed.; Cornils, B., Herrmann, W. A. Eds.; Wiley- VCH: Weinheim, 2002, 1, p. 285.

16. a) Furlani, A.; Napoletano, C.; Russo, M. V.; Camus, A.; Marsich, N. J. Polym. Sci., Part A: Polym. Chem. 1989, 27, 75-86. b) Furlani, A.; Napoletano, C.; Russo, M. V.; Feast, W. J. Polym. Bull. 1986, 16, 311-317.

17. Katayama, H.; Yamamura, K.; Miyaki, Y.; Ozawa, F. Organometallics 1997, 16, 4497-4500.

18. a) Goldberg, Y.; Alper, H. J. Chem. Soc., Chem. Commun. 1994, 1209-1210. b) Kishimoto, Y.; Itou, M.; Miyatake, T.; Ikariya, T.; Noyori, R. Macromolecules 1995, 28, 6662-6666.

19. a) Kishimoto, Y.; Eckerle, P.; Miyatake, T.; Ikariya, T.; Noyori, R. J. Am. Chem. Soc. 1994, 116, 12131-12132. b) Kishimoto, Y.; Miyatake, T.; Ikariya, T.; Noyori, R. Macromolecules 1996, 29, 50545055. c) Kishimoto, Y.; Eckerle, P.; Miyatake, T.; Kainosho, M.; Ono, A.; Ikariya, T.; Noyori, R. J. Am. Chem. Soc. 1999, 121, 12035-12044.

20. a) Misumi, Y.; Masuda T. Macromolecules 1998, 31, 7572-7573. b) Misumi, Y.; Kanki, K.; Miyake, M.; Masuda, T. Macromol. Chem. Phys. 2000, 201, 2239-2244.

21. Miyake, M.; Misumi, Y.; Masuda, T. Macromolecules 2000, 33, 6636-6639.

22. Saeed, I.; Shiotsuki, M.; Masuda, T. Macromolecules 2006, 39, 8567-8573.

23. Jiménez, M. V.; Pérez- Torrente, J. J.; Bartolomé, M. I.; Vispe, E.; Lahoz, F. J.; Oro, L. A. Macromolecules 2009, 42, 8146-8156.

24. Rédrová, D.; Sedláček, J.; Žigon, M.; Vohlídal, J. Collect. Czech. Chem. Commun. 2005, 70, 1787-1798. 
25. We thank Wyatt Technology Inc. of Santa Barbara, CA for a generous loan of this equipment to the Instituto Universitario de Catálisis Homogénea.

26. For degradation of PPA in solution and the bulk state see Percec, V.; G. Rudick, J. G. Macromolecules 2005, 38, 7241-7250.

27. See Podzimek, S.; Vlcek, T.; Johann, C. J. Appl. Polym. Sci. 2001, 81, 1588- 94 and references therein.

28. It should be noted that the slope of the linear portions of these conformation plots varied between 0.55 and 0.65 in THF solution. Normally one would expect a slope of ca. 0.58 for a linear polymer in a good solvent. We suspect the variation reflects the complexity of PPA behavior seen in dilute solution where both mass and size can be time and solvent dependent, reflecting s- trans to s- cis isomerization accompanied by changes to solvent- polymer and polymer- polymer interactions. See Cametti, C.; Codastefano, P.; D’Amato, R.; Furlani, A.; Russo, M.V. Synthetic Metals 2000, 114, 173-179.

29. Since the MALS detector signal is divided by the signal from the DRI detector to produce a signal proportional to molar mass, large and systematic errors can be expected whenever the former signal is non-zero, and the latter signal very close to zero and/or dominated by noise.

30. The origins of these bimodal MMD are not known. Evidently there are two species that independently propagate, but since the relative amounts did not obviously correlate with the experimental conditions (solvent, T or presence of water), it is a matter of speculation as to what the two species may be.

31. See Supporting Information for details: Zimm, B. H. and Stockmayer, W. H., J. Chem. Phys. 1949, 17, 1301-14.

32. Komatsu, H.; Suzuki, Y.; Yamazaki, H. Chem. Lett. 2001 998-999.

33. Kumar, V.G.; Shoba, T.S.; Bao, K.V.C. Tetrahedron Lett.1985, 26, 6245-6248. 
34. Zhan, X.; Yang, M. J.Mol. Cat. A: Chem. 2001, 169, 57-62 and references therein. 


\section{Branched Poly(phenylacetylene)}

Marta Angoy, M. Isabel Bartolomé, Eugenio Vispe, Petr Lebeda, M. Victoria Jiménez,* Jesús J. PérezTorrente, Scott Collins, * and Stepan Podzimek.
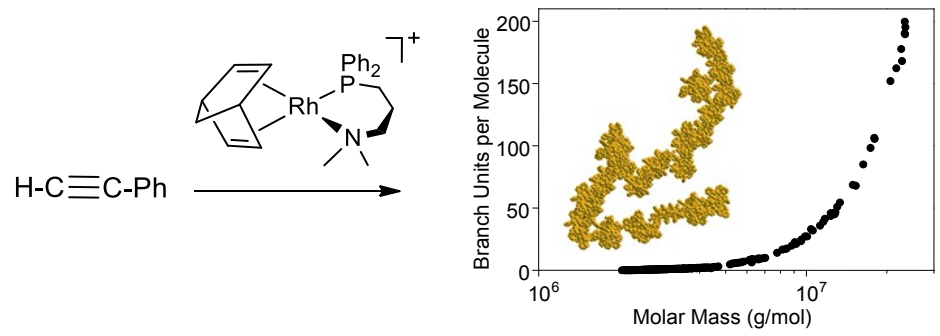

Linear and branched poly(phenylacetylene) are produced using $\mathrm{Rh}(\mathrm{I})$ catalysts bearing hemilabile ligands. The branching frequencies and their dependence on molar mass are consistent with terminal branching through copolymerization of macromonomer, or chain transfer to polymer. 